\title{
Self-excited noise generation from laminar methane/air premixed flames in thin annular jets
}

\author{
Seong-Ho Jin* \\ School of Engineering \\ University of Lincoln \\ Lincoln, LN6 7TS, UK \\ Jae-Hoon Joung \\ School of Mechanical and Aerospace Engineering \\ Seoul National University \\ Seoul, 151-742, Korea \\ Suk-Ho Chung \\ Clean Combustion Research Centre \\ King Abdullah University of Science and Technology \\ Thuwal 23955-6900, Kingdom of Saudi Arabia
}

\begin{abstract}
Self-excited noise generation from laminar flames in thin annular jets of premixed methane/air has been investigated experimentally. Various flame shapes were observed in this flow configuration, including conical shaped flames, ring shaped flames, steady crown shaped flames, and oscillating crown shaped flames. Self-excited noise with a total sound pressure level of about $70 \mathrm{~dB}$ was generated from the oscillating crown shaped flames for equivalence ratios larger than 0.95 . Sound pressure and $\mathrm{CH}^{*}$ chemiluminescence were measured by using a microphone and a photomultiplier tube. The frequency of generated noise was measured as a function of equivalence ratio and premixture velocity. A frequency doubling phenomenon has also been observed. The measured $\mathrm{CH}^{*}$ chemiluminescence data were analysed and which the corresponding sound pressure has been calculated. By comparing the measured and calculated sound pressures, the noise source can be attributed to the flame front fluctuation near the edge of the oscillating crown shaped flames. The flame stability regime was influenced strongly by the mass flow rate of air through the inner tube.
\end{abstract}

Keywords: Annular jet; Laminar premixed flame; Sound pressure; Stability

\footnotetext{
* Corresponding author. E-mail: sjin@lincoln.ac.uk
} 


\section{NOMENCLATURE}

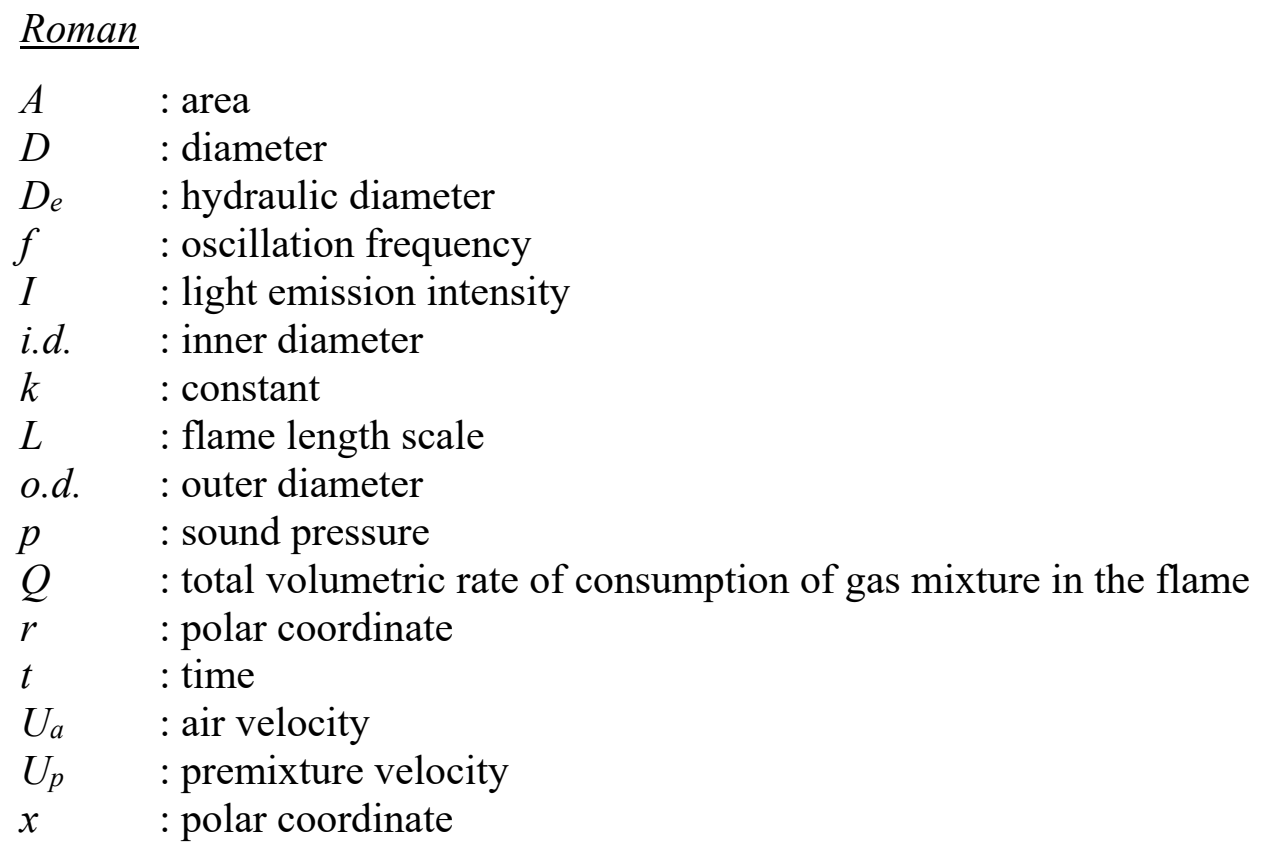

\section{$\underline{\text { Greek }}$}

$\phi \quad$ : equivalence ratio (actual fuel/air ratio over ideal fuel/air ratio)

$\varphi \quad$ : phase angle

$\lambda \quad$ : acoustic wavelength

$v \quad:$ kinematic viscosity

$\rho \quad$ : density

$\tau \quad:$ time required for the sound wave to propagate to the measurement point

\section{$\underline{\text { Subscripts }}$}

$\begin{array}{ll}a & : \text { air } \\ b & : \text { burned } \\ \text { in } & : \text { inner } \\ \text { out } & : \text { outer } \\ p & : \text { premixture } \\ u & : \text { unburned }\end{array}$

\section{$\underline{\text { Abbreviations }}$}

FFT : fast Fourier transform

$F W H M$ : full width at half maximum

$P M T$ : photomultiplier tube 


\section{INTRODUCTION}

Recent demands for high combustion loads and stringent emission requirements frequently induce combustion instabilities. Since these are undesirable sources of noise and can sometimes cause disastrous destruction of combustion equipment, active control of combustion instabilities becomes one of the key interests in combustion research. In order to develop effective control technologies, it is required to understand the mechanisms and the influencing factors governing combustion instabilities.

Previous studies on unsteady combustion instabilities have frequently focused on propulsion systems such as rocket motors [1-3], jet engine afterburners [4, 5], and ramjets [69]. These phenomena are coupled by complex, feedback-type interactions between flow, acoustics, and combustion processes. Recently, attention has been focused on the source of combustion noise by investigating relatively simple and well-defined flow geometries [10-12]. The investigation of laminar jet flames impinging on a cool plate has shown that the source of sound generation is from periodic sudden extinction of large portion of the flame interacting with the cool plate [13]. The response of burner-stabilized flat flames to acoustic velocity perturbations has also been investigated numerically and analytically [14]. These studies utilized the forcing of the flow fields by acoustic speakers. Studies of self-excited combustion noise generation in simple laminar flow geometries are rather limited.

Although multi-coaxial burners are widely used in the field of material synthesis such as fine particle production, not many experimental studies on the characteristics of the related flames have been conducted $[15,16]$. In this study, the characteristics of various flames that can be formed in a double coaxial burner were investigated, and the structure and stability of the flame were investigated.

This type of flow geometry has been investigated previously in terms of flame 
stabilization [17]. Self-excited combustion noise has been generated which depends on the equivalence ratio and jet velocity $[18,19]$. The present study focuses on the self-excited noise generation in the burner, especially the regimes and overall characteristics of noise generation.

\section{EXPERIMENTAL APPARATUS}

The apparatus consisted of an annular jet burner and flow controllers, a visualization setup, and a sound pressure measurement system. The annular jet burner, shown schematically in Fig. 1, was composed of double concentric tubes, which were made of brass. The inner tube is $400 \mathrm{~mm}$ long with i.d. $10.1 \mathrm{~mm}$ and o.d. $10.9 \mathrm{~mm}$. The outer tube was 300 mm long with i.d. $12.8 \mathrm{~mm}$ and o.d. $13.8 \mathrm{~mm}$. The resonance frequency of the inner tube was $425 \mathrm{~Hz}$. The annular slit width was $0.95 \mathrm{~mm}$ and the exit area of the annulus was $A=$ $35.37 \mathrm{~mm}^{2}$. The concentricity of the two tubes was maintained by a set of screws installed at the upstream end of the outer tube.

The fuel was chemical grade ( $>99.95 \%)$ methane. Compressed air was used as an oxidizer. Fuel and air were metered using mass flow controllers, which were calibrated with a wet-test gas meter. A honeycomb and glass beads were installed in the annulus to ensure premixing. The fuel/air mixture was supplied through annulus and the air was supplied through the inner tube. The equivalence ratio and velocities of the premixture and air were the parameters in observing the flame behaviour.

The chemiluminescence signals from $\mathrm{CH}^{*}$ radicals were measured using a photomultiplier tube $(\mathrm{PMT})$ with a band-pass filter $(431 \mathrm{~nm}, \mathrm{FWHM}=5 \mathrm{~nm}) . \quad$ The PMT was positioned at the radial location of $r=27 \mathrm{~cm}$ and the axial location of $X=3 \mathrm{~cm}$ from the center of the nozzle exit. The signal was sampled at $8.19 \mathrm{kHz}$. The flame images were 
taken with an ICCD camera (Princeton Instruments).

For the measurement of sound pressure, a microphone (4189, B\&K) was used. The microphone was placed at $r=31 \mathrm{~cm}$ and $X=3 \mathrm{~cm}$. Instantaneous sound pressure signals were recorded at the sampling rate of $8.19 \mathrm{kHz}$ with a spectral resolution of $0.5 \mathrm{~Hz}$. The sampling duration was 2 seconds.

\section{RESULTS AND DISCUSSION}

\subsection{Observed Flames}

Various flame types have been observed depending on the equivalence ratio $\phi$ and mixture velocity $U_{p}$. Direct photographs of typical flame types are shown in Fig. 2 for the air velocity in the inner tube $U_{a}=0$. The Reynolds number is defined as $U_{p} \cdot D_{e} / v$, where $v$ is the kinematic viscosity, $D_{e}$ is the hydraulic diameter based on the flow rate, that is, $D_{e}=D_{\text {out }}-$ $D_{\text {in }}, D_{\text {out }}$ is the i.d of the outer tube, and $D_{\text {in }}$ is the o.d. of the inner tube. The Strouhal number is defined as $f \cdot D_{e} / U_{p}$, where $f$ is the oscillation frequency. For the experimental conditions of $U_{p}=1.0-4.0 \mathrm{~m} / \mathrm{s}$, the Reynolds number is in the range of $125-500$, and the Strouhal number is in the range of $0.2-0.4$. Although not shown, the Schlieren images confirmed that the flow was laminar within this range.

For $\phi=1.6$ and $U_{p}=1.4 \mathrm{~m} / \mathrm{s}(\mathrm{a})$, the rich premixed flame has a near conical shape with a diffusion flame surrounding it. Note that the flame is attached along the outer rim and is lifted at the inner rim. As $U_{p}$ increases, the flame becomes elongated and finally blows off. For $\phi=1.2$ and $U_{p}=1.2 \mathrm{~m} / \mathrm{s}(\mathrm{b})$, the rich premixed flame had a ring shape with a diffusion flame surrounding it. The rich premixed flame is attached at both the inner and outer rims. For $\phi=1.14$ and $U_{p}=1.8 \mathrm{~m} / \mathrm{s}(\mathrm{c})$, the premixed flame has a crown shape, which is attached at the inner rim and lifted at the outer rim. A diffusion flame is attached near the downstream 
edge of the crown shaped flame. These three types of flames have been observed previously $[18]$.

With a further increase of $U_{p}$ to $2.5 \mathrm{~m} / \mathrm{s}$ at $\phi=1.14(\mathrm{~d})$, the flame becomes unsteady having a fluctuation near the downstream edge of the crown shaped flame. In such cases, especially for $\phi>0.95$, appreciable sound noise has been generated having a total sound pressure level of about $70 \mathrm{~dB}$ as compared to the background noise level of about $50 \mathrm{~dB}$. This self-excited noise generating flame is the focus of the present study. To examine the possibility of the noise being generated by acoustic resonance of the inner tube, a test was performed in which the inner nozzle exit was plugged. The noise generation persisted, suggesting that it is not due to resonance of the inner tube.

The regime of the noise generating flame is shown in Fig. 3 in terms of equivalence ratio and mixture velocity. Regime I is the region for either the ring or conical shape, which has been investigated previously $[18,19]$. As $U_{p}$ increases for $0.8<\phi<1.25$, the flame was changed from steady outer lifted flame (regime II) to the oscillating outer lifted flame (regime III). For $1.25<\phi<1.4$, the flame undergoes transition from the ring or conical shape (regime I) to the oscillating outer lifted flame and finally blowoff occurs as $U_{p}$ increases. For $\phi>1.4$, the ring shaped flame approaches a conical shape and blowoff occurs as $U_{p}$ increases. Although not shown in this figure, the flame has either a crown shape or a ring shape for $U_{p}<1 \mathrm{~m} / \mathrm{s}$. The frequency doubling behaviour in regime III will be discussed later.

\subsection{Noise-Generating Flame}

The total sound pressure levels of the unsteady crown shaped flame for $\phi=1.12,1.14$ and 1.16 are shown in Fig. 4. Two points are to be noted. First, the total sound pressure level is reasonably insensitive to the variation in the mixture velocity, even though a slightly 
increasing trend is observed with $U_{p}$. The background noise level marked as the dashed line is about $50 \mathrm{~dB}$. This level is nearly unchanged for both the steady flame cases and the cold jets without combustion. Compared to this level, the total sound pressure level is about 20 $\mathrm{dB}$ higher for the unsteady crown shaped flames. The second point is that the velocity at the onset of noise generation is sensitive to the equivalence ratio.

The noise generation characteristics are analysed further. The sound pressure level (SPL) in terms of frequency is presented in Fig. 5, demonstrating the spectral distributions at several equivalence ratios $(\phi=1.12,1.14$ and 1.16$)$ and mixture velocities $\left(U_{p}=2.6\right.$ and 3.2 $\mathrm{m} / \mathrm{s}$ ). The SPL shows several discrete peaks, which are labelled with their frequency value. These peaks are embedded in the background noise level, which generally decreases with frequency. The peaks in the sound spectra are strongly influenced by the equivalence ratio and mixture velocity. For $U_{p}=2.6 \mathrm{~m} / \mathrm{s}$, the fundamental frequency is $231.5 \mathrm{~Hz}$ with a level of about $50 \mathrm{~dB}$ for $\phi=1.12$ (a). The fundamental frequency becomes $215 \mathrm{~Hz}$ for $\phi=1.14$ (b) with an SPL of about $60 \mathrm{~dB}$. The SPL of the second harmonic at $430 \mathrm{~Hz}$ is comparable to that of the fundamental frequency. For $\phi=1.16$ (c), the SPL at $410.5 \mathrm{~Hz}$ becomes higher than that at $205.5 \mathrm{~Hz}$. As the mixture velocity increase to $U_{p}=3.2 \mathrm{~m} / \mathrm{s}$, the SPL of the fundamental frequency at $241 \mathrm{~Hz}$ increases up to $68 \mathrm{~dB}$ for $\phi=1.12$ (d). For $\phi=1.14$ (e), the SPL of the fundamental frequency at $228 \mathrm{~Hz}$ dominates over that of the second harmonic. For $\phi=1.16$ (f), the SPL at $428 \mathrm{~Hz}$ mainly remains. Figure 6 shows the frequency of the peak sound pressure level as a function of mixture velocity. The results show the frequency doubling behaviour for the unsteady crown shaped flames as mixture velocity increases for $\phi$ $=1.16$, and this trend persists for $\phi>1.16$ for the present experimental range. This point will be discussed further later. 


\section{3. $\mathrm{CH}^{*}$ Chemiluminescence}

The characteristics of the unsteady crown shape flame are analysed further. The $\mathrm{CH}^{*}$ chemiluminescence signal shows periodic oscillation, and one cycle is shown in Fig. 7. The ICCD images at several phase angles $\varphi$ are also exhibited corresponding to the unsteady flame shown in Fig. 2d. The $\mathrm{CH}^{*}$ signal shows near sinusoidal behaviour and the corresponding flame shapes demonstrate a series of flame surface variation, especially near the downstream part of the flame surface. The waist part of the flame surface starts to corrugate at $\varphi=5 \pi / 4$, and this corrugation is amplified as it is convected downstream. The curved flame surface is deflected in such a way that a part of the flame surface is pointing upstream, e.g., at the phase angle $\varphi$ between $\pi / 4$ and $5 \pi / 4$, indicating that the flame edge region fluctuates appreciably.

Since the $\mathrm{CH}^{*}$ chemiluminescence could reasonably represent the flame-shape variation, the signals are further analysed at various test conditions. Figure 8 shows the frequencies of $\mathrm{CH}^{*}$ chemiluminescence signals in terms of mixture velocity from the fast Fourier transform (FFT) of the $\mathrm{CH}^{*}$ signals. The general behaviour agrees qualitatively with the frequency of sound pressure level shown in Fig. 6, in terms of the variation of frequency with equivalence ratio and mixture velocity. However, note that the premixture velocity at the onset of frequency doubling $U_{p}$ is shifted toward a higher value, e.g., $U_{p} \approx 2.1 \mathrm{~m} / \mathrm{s}$ from the sound pressure in Fig. 6 , while $U_{p} \approx 2.7 \mathrm{~m} / \mathrm{s}$ from the $\mathrm{CH}^{*}$ in Fig. 8 for $\phi=1.16$. This can be attributed to the FFT behaviour of the sound and $\mathrm{CH}^{*}$ signals. The audible sound could clearly distinguish the frequency doubling through the change in the pitch of noise. This judgement is found to be closely related to the change in the sound pressure level. The boundary of the frequency doubling from the audible noise is marked in Fig. 3 as the dotted line. 


\section{4. $\mathrm{CH}^{*}$ Chemiluminescence and Sound Pressure}

Variations of sound pressure and $\mathrm{CH}^{*}$ signal with time are compared in Fig. 9 at several combinations of equivalence ratio and mixture velocity. Both signals fluctuate with time. Case (a) shows periodic behaviour for the $\mathrm{CH}^{*}$ chemiluminescence and cases $(\mathrm{b}-\mathrm{e})$ clearly show frequency doubling behaviour. Case (f) again shows periodic behaviour, but with higher frequency. This behaviour agrees well with that of the peaks in the sound spectra shown in Fig. 5. The behaviour of sound pressure closely resembles that of the $\mathrm{CH}^{*}$ chemiluminescence. The sound pressure is in phase with $\mathrm{CH}^{*}$ chemiluminescence.

The mechanism of sound generation in premixed flames has been investigated by analysing the light emission from the flames. Price et al. [20] provided the following relation between the sound pressure $p$ radiated from a freely propagating flame and the heat release

$$
p(r, t)=\frac{\rho_{\infty}}{4 \pi r}\left(\frac{\rho_{u}}{\rho_{b}}-1\right)\left[\frac{d Q}{d t}\right]_{t-\tau}
$$

where $r$ is the distance between the flame and the microphone, $t$ is the time, $\rho_{\infty}$ is the far field air density, $\rho_{w} / \rho_{b}$ is the volumetric expansion ratio of unburnt to burnt gases, $Q$ is the total volumetric rate of consumption of gas mixture in the flame, and $\tau$ is the time required for the sound wave to propagate from the flame to the measurement point $r$. Here, it is assumed that the acoustic wavelength $\lambda$ is large compared to flame length scale $L$ and the measurement point $r$ is far from all sources.

The rate of variation $d Q / d t$ is modelled assuming that $Q$ is proportional to the light- 
emission intensity $I$ of free radicals $\mathrm{CH}^{*}$ or $\mathrm{C}_{2} *$ in the reaction zone,

$$
Q=k I
$$

where $k$ is a constant for a given equivalence ratio and is determined from a plot of mean emission intensity $I$ versus mean flow rate. This relation is often used to deduce an estimate of heat release rate $[13,21]$. These two relations result in:

$$
p(r, t)=\frac{\rho_{\infty}}{4 \pi r}\left(\frac{\rho_{u}}{\rho_{b}}-1\right) k\left[\frac{d I}{d t}\right]_{t-\tau}
$$

This indicates that the sound pressure signal can be estimated from the variation of the light emission from a flame.

By adopting this approach, the $\mathrm{CH}^{*}$ chemiluminescence signals are further analyzed using Eq. (3), through which the sound pressures can be calculated from the $\mathrm{CH}^{*}$ signals. Figure 10 shows the comparison of the calculated and measured sound pressures. The results show reasonable agreement between the two sound pressures, even with the limitations in the sound pressure measurements. When the sound pressure was measured, the directivity effect was not considered due to experimental limitations: the experiment was not performed in an anechoic chamber and the far-field approximation $(r>\lambda)$ in Eq. (3) is not strictly valid with the present microphone location of $r=31 \mathrm{~cm}$. Note that this distance is comparable to the previous measurement [13], to minimize the influence of acoustic reflection from surroundings. The close resemblance between the measured and calculated sound pressure implies that the noise is generated by the flame surface fluctuation. 


\subsection{Effect of Air Flow in the Inner Tube}

Introducing a supply of air through the inner tube affects the stability boundary. Figure 11 shows direct photographs at various air velocity for $\phi=1.14$ and $U_{p}=2.5 \mathrm{~m} / \mathrm{s}$. As mentioned previously, the outer lifted flame was oscillated for $U_{a}=0$ in this condition. With the supply of air through the inner tube, the flame becomes stationary for $U_{a}=0.01 \mathrm{~m} / \mathrm{s}$ (a). This stationary flame persists up to $U_{a}$ increases to about $0.095 \mathrm{~m} / \mathrm{s}$ (b). The flame becomes unsteady again for $U_{a}=0.10 \mathrm{~m} / \mathrm{s}(\mathrm{c})$, such that audible noise is again generated. As the air velocity further increases, the noise becomes intensified. Finally, the flame becomes irregular (d) and blowout occurs for $U_{a}>0.20 \mathrm{~m} / \mathrm{s}$.

Figure 12 shows the frequency, sound pressure level, and amplitude of $\mathrm{CH}^{*}$ signal as a function of air velocity for $\phi=1.14$ and $U_{p}=2.5 \mathrm{~m} / \mathrm{s}$. As the air velocity increases, the flame undergoes transition from unsteady to steady and then to unsteady behaviour. For $U_{a}$ $\geq 0.10 \mathrm{~m} / \mathrm{s}$, the frequency decreases and the sound pressure level increases with increasing air velocity. Note that for $U_{a} \geq 0.10 \mathrm{~m} / \mathrm{s}$, the frequency becomes less than the half of that for the small $U_{a}$, even though the sound pressure level becomes comparable.

Figure 13 shows the stability diagrams for $U_{a}=0.03$ and $0.10 \mathrm{~m} / \mathrm{s}$. Compared to Fig. 3 for $U_{a}=0$, regime $\mathrm{I}$, having either ring or conical shape flame, is relatively unchanged. Regime II (steady crown shaped flames) initially expands (a) and then shrinks and shifts to richer side, and consequently regime III (unsteady oscillating crown shaped flames) expands. The initial blowout regime also shifts toward the richer side. At relatively high $U_{a}$, e.g., $U_{a}$ $=0.10 \mathrm{~m} / \mathrm{s}$, another blowout regime appears for small $U_{p}$ and $\phi . \quad$ Although not shown here, this region expands as $U_{a}$ is increased further. 


\section{CONLUDING REMARKS}

Premixed methane/air flames in the laminar thin annular jet burner have been studied experimentally to investigate the characteristics of self-excited noise generation. The flame in the annular jets has various flame shapes, including ring shaped, near conical shaped, crown shaped, and oscillating crown shaped depending on equivalence ratio, mixture velocity and air velocity. The regimes of the existence of these flames were identified. Self-excited noise with an SPL of about $70 \mathrm{~dB}$ was generated for the unsteady crown shaped flame when the mixture was rich. Frequency of the sound pressure depended on the equivalence ratio and mixture velocity. The frequency doubling behaviour occurred for richer mixtures. The variation of sound pressure with time showed similar behaviour to that of the $\mathrm{CH}^{*}$ chemiluminescence. The calculated sound pressure from the $\mathrm{CH}^{*}$ chemiluminescence signal was in satisfactory agreement with the measured one, demonstrating the source of sound generation is from the flame surface fluctuation near the downstream part of the crown shape flames. The present study demonstrates that significant noise can be generated when a rich fuel/air mixture is burnt in air. Further study is needed in the future to identify the mechanism of flame surface corrugation, the noise source location, the interaction with the diffusion flame surrounding it, and the mechanism of frequency doubling.

\section{REFERENCES}

1. H. Tsuji, T. Takeno, An experimental investigation on high-frequency combustion oscillations, Tenth Symposium (International) on Combustion, The Combustion Institute, Pittsburgh, 1964, p. 1327-1335. https://doi.org/10.1016/S0082$\underline{0784(65) 80267-3}$

2. L. Crocco, S. Cheng, Theory of Combustion Instability in Liquid Propellant Rocket Motors, Butterworths Scientific Publications, London, U.K., 1956. ISBN: 1124091505

3. B.T. Zinn, E.A. Powell, Nonlinear combustion instability in liquid-propellant rocket engines, Thirteenth Symposium (International) on Combustion, The Combustion 
Institute, Pittsburgh, 1970, p. 491-503. https://doi.org/10.1016/S0082-0784(71)80051-6

4. P.J. Langhorne, Reheat buzz: an acoustically coupled combustion instability. Part 1.

Experiment, J. Fluid Mech. 193 (1988) 417-443.

https://doi.org/10.1017/S0022112088002204

5. G.J. Bloxsidge, A.P. Dowling, P.J. Langhorne, Reheat buzz: an acoustically coupled combustion instability. Part 2. Theory, J. Fluid Mech. 193 (1988) 445-473. https://doi.org/10.1017/S0022112088002216

6. V. Yang, F.E. Culick, Analysis of low frequency combustion instabilities in a laboratory ramjet combustor, Comb. Sci. and Tech. 45 (1986) 1-25.

https://doi.org/10.1080/00102208608923839

7. K.C. Schadow, K.J. Wilson, E. Gutmark, Characterization of large-scale structures in a forced ducted flow with dump, AIAA Journal 25 (1987) 1164-1170.

https://doi.org/10.2514/3.9763

8. K.C. Schadow, E. Gutmark, Combustion instability related to vortex shedding in dump combustors and their passive control, Prog. Energy Combust. Sci. 18 (1992) 117-132. https://doi.org/10.1016/0360-1285(92)90020-2

9. U.G. Hegde, D. Reuter, B.R. Daniel, B.T. Zinn, Flame driving of longitudinal instabilities in dump type ramjet combustors, Comb. Sci. and Tech. 55 (1987) 125-138. https://doi.org/10.1080/00102208708947075

10. D. Brouzet, A. Haghiri, M. Talei, M.J. Brear, Annihilation events topology and their generated sound in turbulent premixed flames, Combustion and Flame 204 (2019) 268277. https://doi.org/10.1016/j.combustflame.2019.02.028

11. T. Schuller, D. Durox, S. Candel, Self-induced combustion oscillations of laminar premixed flames stabilized on annular burners, Combust. Flame 135 (2003) 525-537. https://doi.org/10.1016/j.combustflame.2003.08.007

12. S. Candel, D. Durox, T. Schuller, Flame interactions as a source of noise and combustion instabilities, $10^{\text {th }}$ AIAA/CEAS Aeroacoustics Conference, 2004, 2928. https://doi.org/10.2514/6.2004-2928

13. T. Schuller, D. Durox, S. Candel, Dynamics of and noise radiated by a perturbed impinging premixed jet flame, Combust. Flame 128 (2002) 88-110. https://doi.org/10.1016/S0010-2180(01)00334-0

14. R. Rook, L.P.H. Goey, L.M.T. Somers, K.R.A.M. Schreel, R. Parchen, Response of burner-stabilized flat flames to acoustic perturbations, Combust. Theory Modelling 6 (2002) 223-242. https://doi.org/10.1088/1364-7830/6/2/305

15. N.K. Memon, D.H. Anjum, S.H. Chung, Multiple-diffusion flame synthesis of pure anatase and carbon-coated titanium dioxide nanoparticles, Combust. Flame 160 (2013) 1848-1856. https://doi.org/10.1016/j.combustflame.2013.03.022 
16. M.A. Ismail, N.K. Memon, M.S. Mansour, D.H. Anjum, S.H. Chung, Curved wall-jet burner for synthesizing titania and silica nanoparticles, Proceedings of the Combustion Institute, Vol. 35, The Combustion Institute, Pittsburgh, 2015, p. 2267-2274. https://doi.org/10.1016/j.proci.2014.05.043

17. Z. Shu, S.K. Aggarwal, V.R. Katta, I.K. Puri, Flame-vortex dynamics in an inverse partially premixed combustor: The Froude number effects, Combust. Flame 111 (1997) 276-295. https://doi.org/10.1016/S0010-2180(97)00018-7

18. S.J. Kwon, M.S. Cha, M.S. Choi, S.H. Chung, Characteristics of premixed flames in a double concentric burner, Trans. KSME (B) 24 (2000) 1662-1669. http://www.dbpia.co.kr/journal/articleDetail?nodeId=NODE00343719

19. S.H. Jin, S.H. Chung, Self-excited noise generation from laminar methane/air premixed flames in thin annular jets, 2003 Australian Symposium on Combustion, 8-9 December (2003) Monash University, Australia.

20. R.B. Price, I.R. Hurle, T.M. Sugden, Optical studies of the generation of noise in turbulent flames, Twelfth Symposium (International) on Combustion, The Combustion Institute, Pittsburgh, 1968, p. 1093-1102. https://doi.org/10.1016/S00820784(69)80487-X

21. S. Ducruix, D. Durox, S. Candel, Theoretical and experimental determinations of the transfer function of a laminar premixed flame, Proceedings of the Combustion Institute, Vol. 28, The Combustion Institute, Pittsburgh, 2000, p. 765-773. https://doi.org/10.1016/S0082-0784(00)80279-9 


\section{FIGURE CAPTIONS}

Figure 1. Schematic of experimental set-up.

Figure 2. Direct photographs of flames in thin annular jet burner; (a) conical shape $(\phi=1.6$, $\left.U_{p}=1.4 \mathrm{~m} / \mathrm{s}\right)$, (b) ring shape $(1.2,1.2 \mathrm{~m} / \mathrm{s})$, (c) steady crown shape $(1.14,1.8$ $\mathrm{m} / \mathrm{s})$, and (d) unsteady crown shape $(1.14,2.5 \mathrm{~m} / \mathrm{s})$.

Figure 3. Regimes of various flames in terms of equivalence ratio and mixture velocity (regime I; ring or conical shape, regime II; steady crown shape, regime III; unsteady crown shape).

Figure 4. Sound pressure level as function of mixture velocity at several equivalence ratios.

Figure 5. Sound spectra at various equivalence ratios and mixture velocities; (a) ( $\phi=1.12$, $U_{p}=2.6 \mathrm{~m} / \mathrm{s}$, (b) $(1.14,2.6 \mathrm{~m} / \mathrm{s}),(\mathrm{c})(1.16,2.6 \mathrm{~m} / \mathrm{s}),(\mathrm{d})(1.12,3.2 \mathrm{~m} / \mathrm{s}),(\mathrm{e})(1.14$, $3.2 \mathrm{~m} / \mathrm{s})$, and (f) $(1.16,3.2 \mathrm{~m} / \mathrm{s})$.

Figure 6. Frequency at maximum sound pressure level as a function of mixture velocity at several equivalence ratios.

Figure 7. Variation of flame shape and $\mathrm{CH}^{*}$ signal as function of phase angle for $\phi=1.14$ and $U_{p}=2.5 \mathrm{~m} / \mathrm{s}$.

Figure 8. Peak frequency from FFT of chemiluminescence of $\mathrm{CH}^{*}$ as function of mixture velocity at several equivalence ratios.

Figure 9. Comparison of $\mathrm{CH}^{*}$ chemiluminescence and sound pressure with time; (a) ( $\phi=$ $1.12, U_{p}=2.6 \mathrm{~m} / \mathrm{s}$, (b) $(1.14,2.6 \mathrm{~m} / \mathrm{s}),(\mathrm{c})(1.16,2.6 \mathrm{~m} / \mathrm{s}),(\mathrm{d})(1.12,3.2 \mathrm{~m} / \mathrm{s}),(\mathrm{e})$ $(1.14,3.2 \mathrm{~m} / \mathrm{s})$, and (f) $(1.16,3.2 \mathrm{~m} / \mathrm{s})$.

Figure 10. Comparison between measured and calculated sound pressures with time; (a) $(\phi$ $=1.12, U_{p}=2.6 \mathrm{~m} / \mathrm{s},(\mathrm{b})(1.14,2.6 \mathrm{~m} / \mathrm{s}),(\mathrm{c})(1.16,2.6 \mathrm{~m} / \mathrm{s}),(\mathrm{d})(1.12,3.2 \mathrm{~m} / \mathrm{s})$, (e) $(1.14,3.2 \mathrm{~m} / \mathrm{s})$, and (f) $(1.16,3.2 \mathrm{~m} / \mathrm{s})$.

Figure 11. Direct photographs of flames with air velocity in inner nozzle for $\phi=1.14$ and $U_{p}$ $=2.5 \mathrm{~m} / \mathrm{s}$; (a) $U_{a}=0.01 \mathrm{~m} / \mathrm{s}$, (b) $0.085 \mathrm{~m} / \mathrm{s}$, (c) $0.10 \mathrm{~m} / \mathrm{s}$, and (d) $0.13 \mathrm{~m} / \mathrm{s}$.

Figure 12. Sound pressure level, frequency, and amplitude of $\mathrm{CH}^{*}$ signal as function of air velocity in inner tube for $\phi=1.14$ and $U_{p}=2.5 \mathrm{~m} / \mathrm{s}$.

Figure 13. Flame stability diagrams for air velocity in inner nozzle of (a) $U_{a}=0.03 \mathrm{~m} / \mathrm{s}$ and (b) $0.1 \mathrm{~m} / \mathrm{s}$ (regime I; ring or conical shape, regime II; steady crown shape, and regime III; unsteady crown shape). 


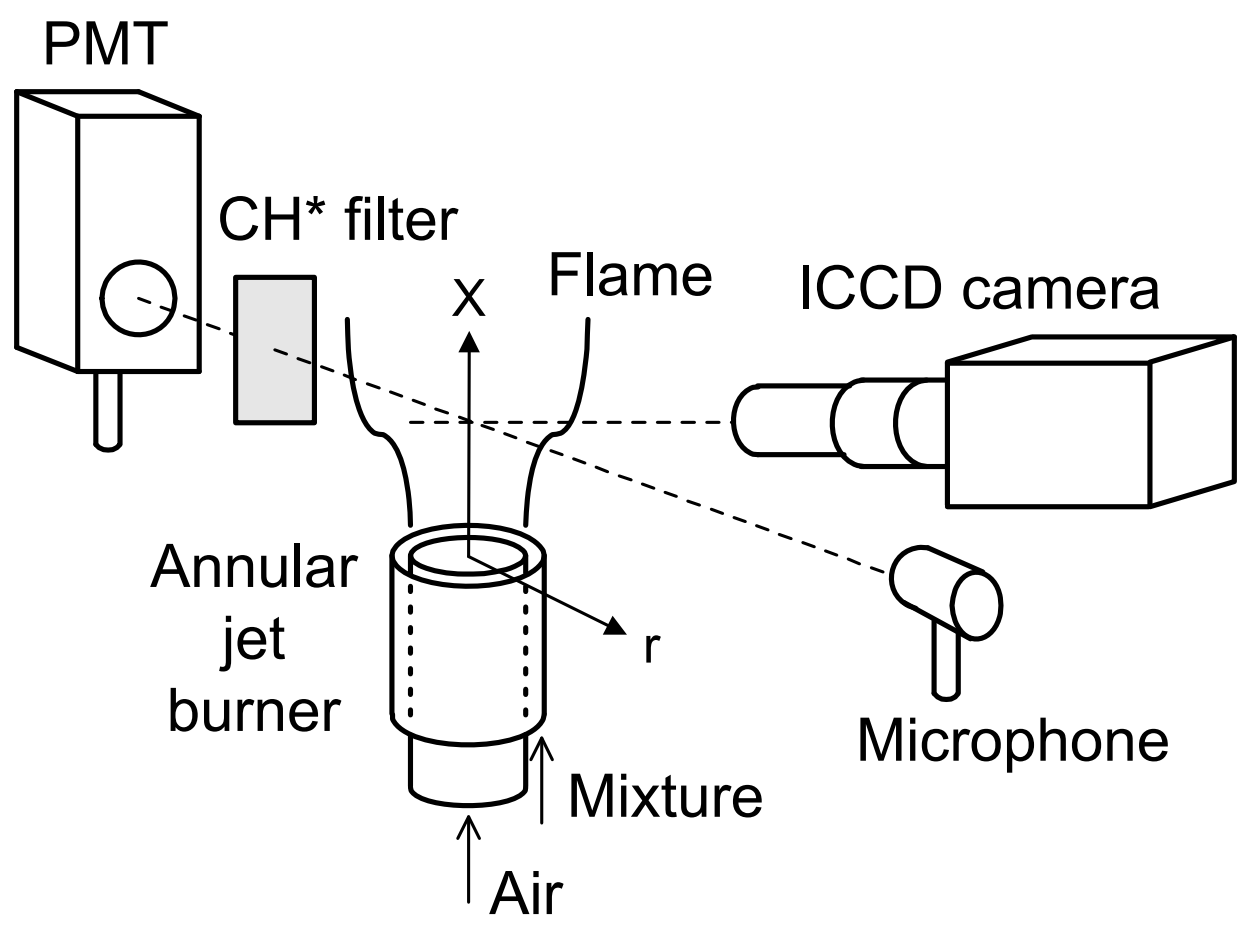

Figure 1. Schematic of experimental set-up. 


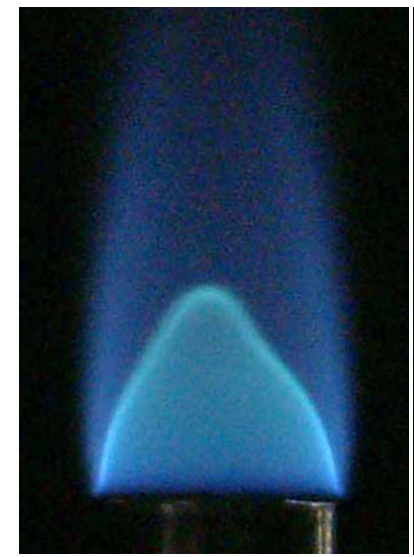

(a)

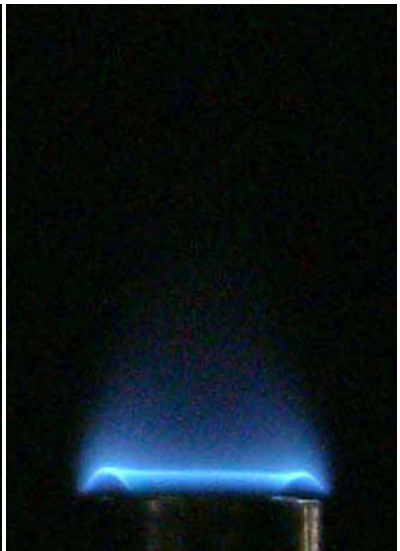

(b)

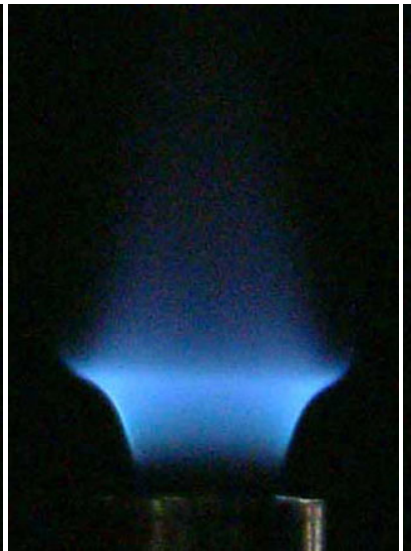

(c)

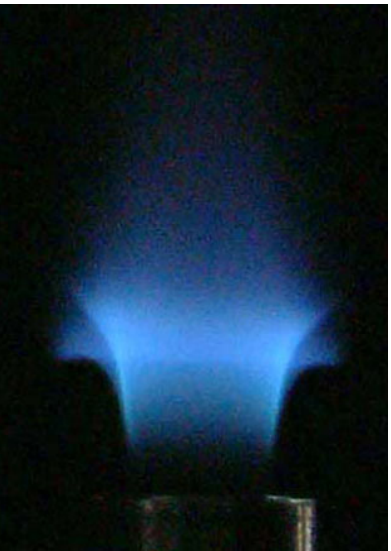

(d)

Figure 2. Direct photographs of flames in thin annular jet burner; (a) conical shape $(\phi=1.6$, $\left.U_{p}=1.4 \mathrm{~m} / \mathrm{s}\right),(\mathrm{b})$ ring shape $(1.2,1.2 \mathrm{~m} / \mathrm{s})$, (c) steady crown shape $(1.14,1.8 \mathrm{~m} / \mathrm{s})$, and (d) unsteady crown shape $(1.14,2.5 \mathrm{~m} / \mathrm{s})$. 


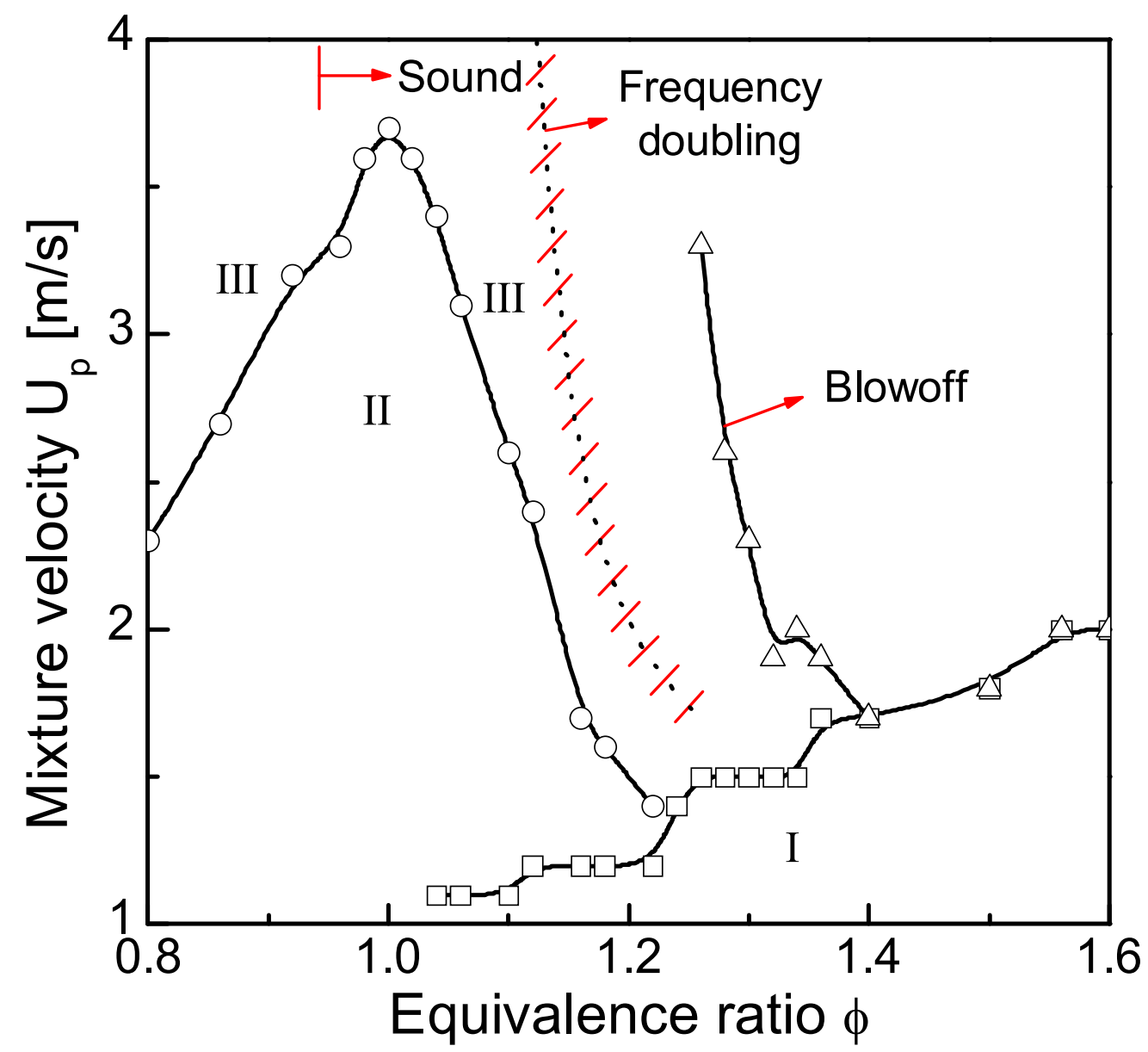

Figure 3. Regimes of various flames in terms of equivalence ratio and mixture velocity (regime I; ring or conical shape, regime II; steady crown shape, regime III; unsteady crown shape). 


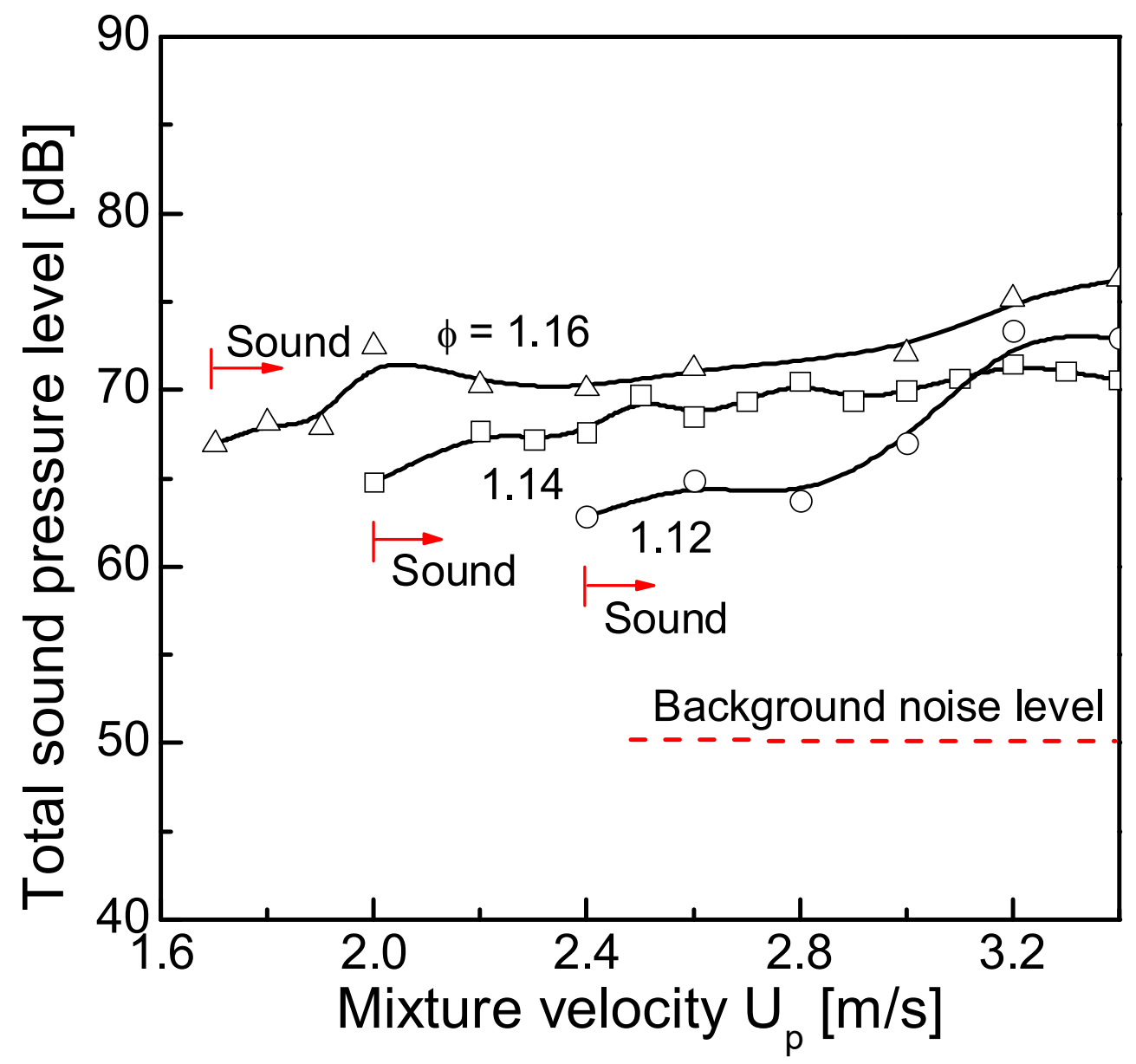

Figure 4. Sound pressure level as function of mixture velocity at several equivalence ratios. 


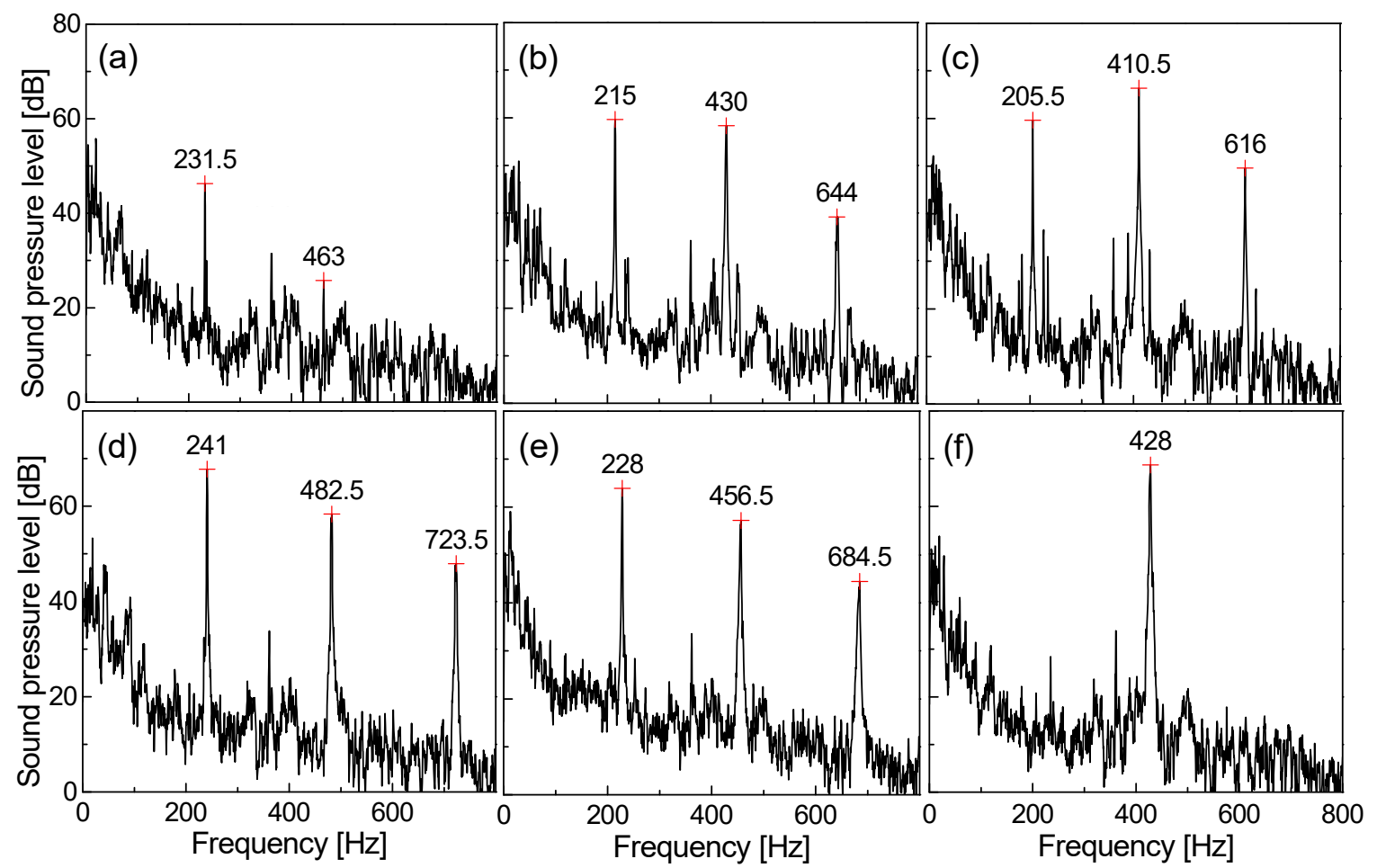

Figure 5. Sound spectra at various equivalence ratios and mixture velocities; (a) ( $\phi=1.12$, $\left.U_{p}=2.6 \mathrm{~m} / \mathrm{s}\right),(\mathrm{b})(1.14,2.6 \mathrm{~m} / \mathrm{s}),(\mathrm{c})(1.16,2.6 \mathrm{~m} / \mathrm{s}),(\mathrm{d})(1.12,3.2 \mathrm{~m} / \mathrm{s}),(\mathrm{e})(1.14,3.2 \mathrm{~m} / \mathrm{s})$, and (f) $(1.16,3.2 \mathrm{~m} / \mathrm{s})$. 


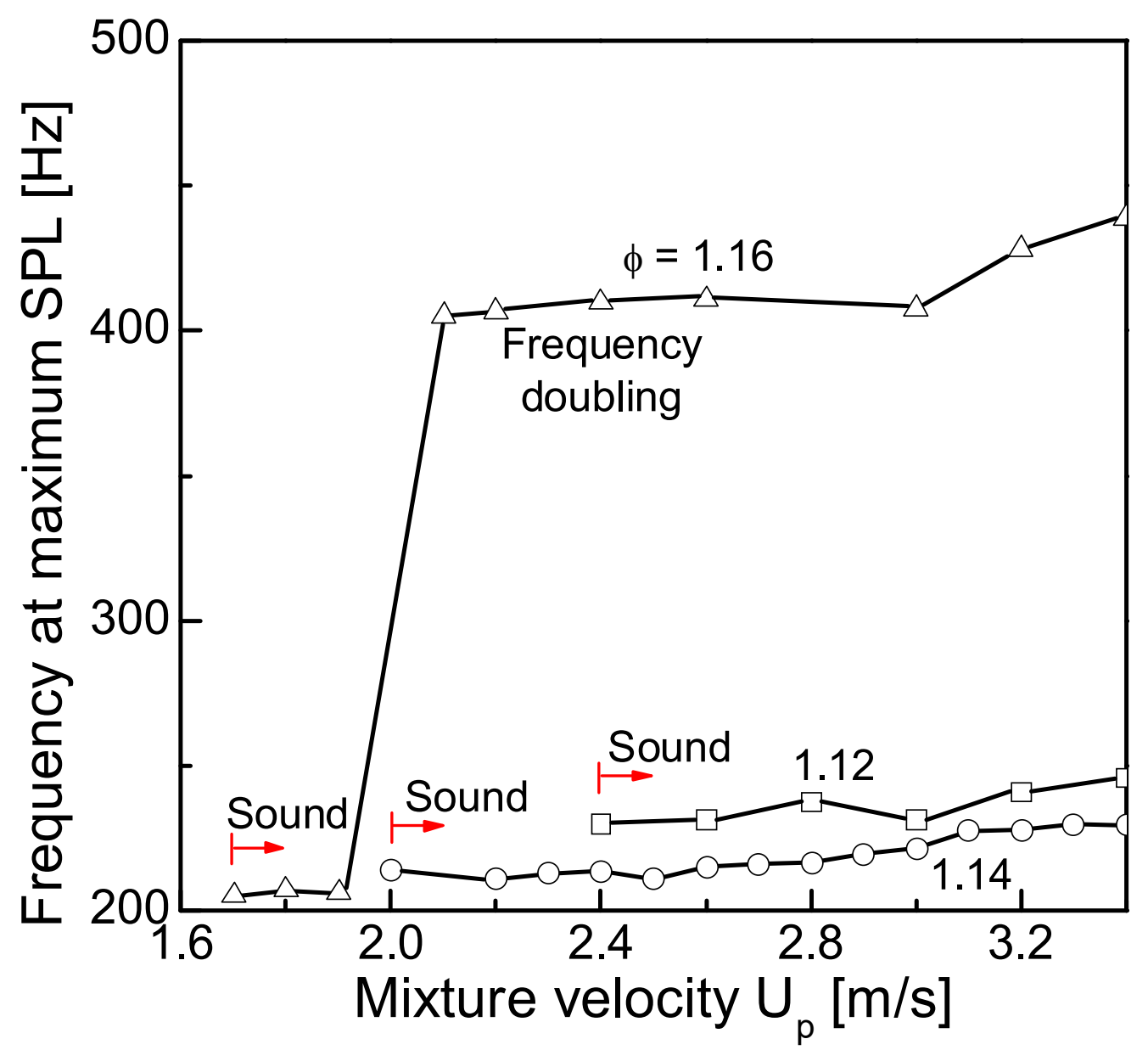

Figure 6. Frequency at maximum sound pressure level as a function of mixture velocity at several equivalence ratios. 

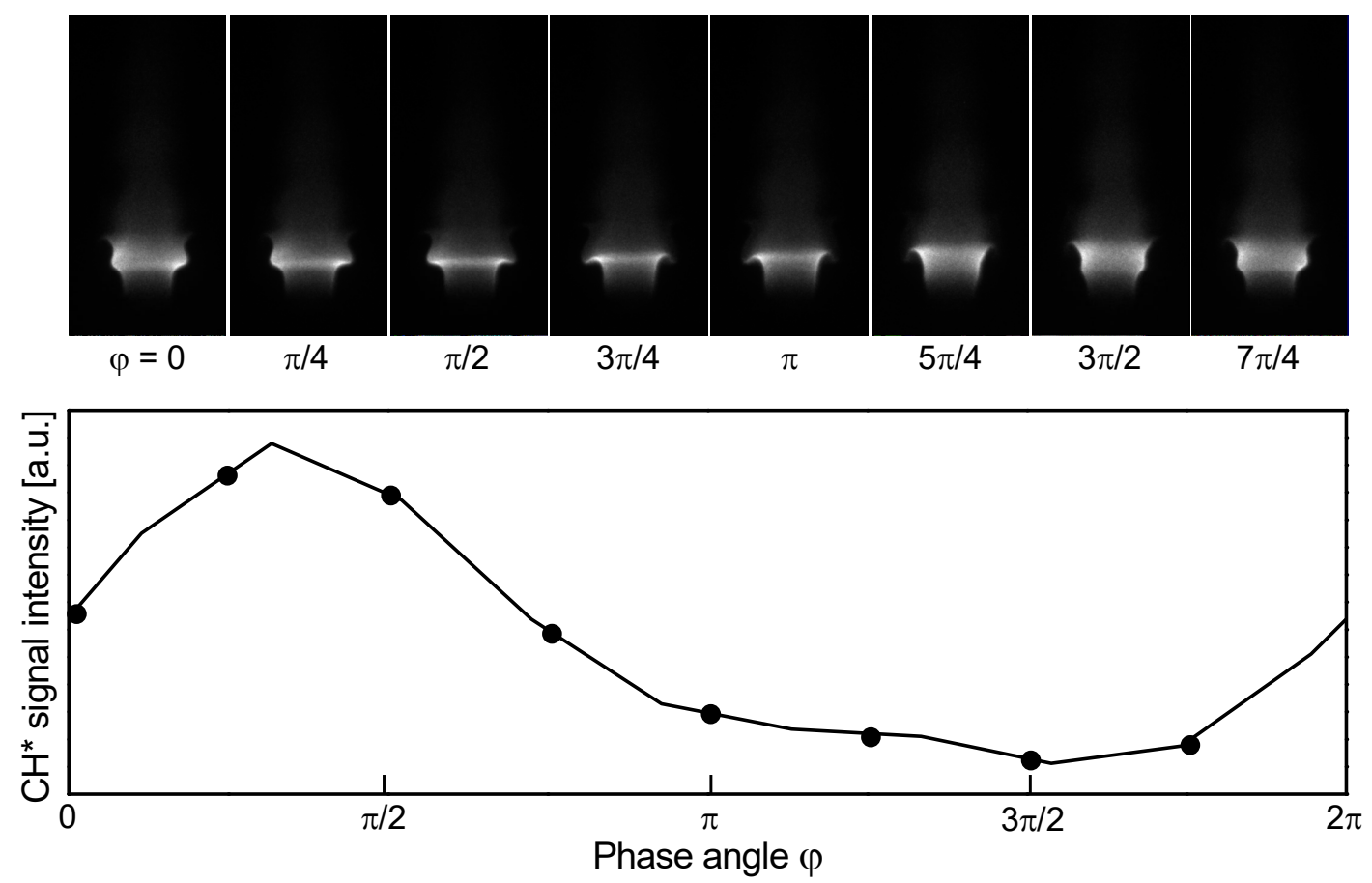

Figure 7. Variation of flame shape and $\mathrm{CH}^{*}$ signal as function of phase angle for $\phi=1.14$ and $U_{p}=2.5 \mathrm{~m} / \mathrm{s}$. 


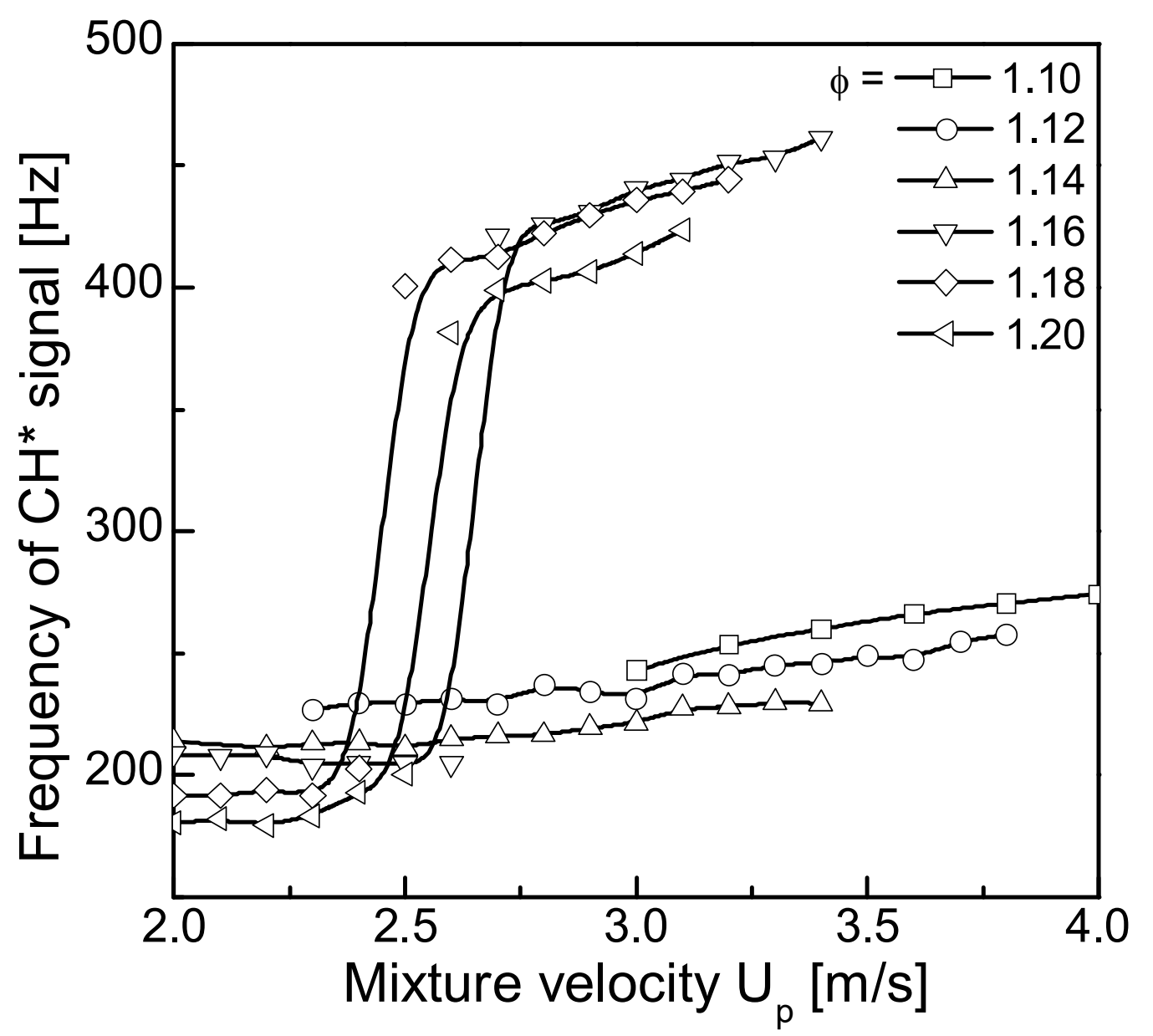

Figure 8. Peak frequency from FFT of chemiluminescence of $\mathrm{CH}^{*}$ as function of mixture velocity at several equivalence ratios. 


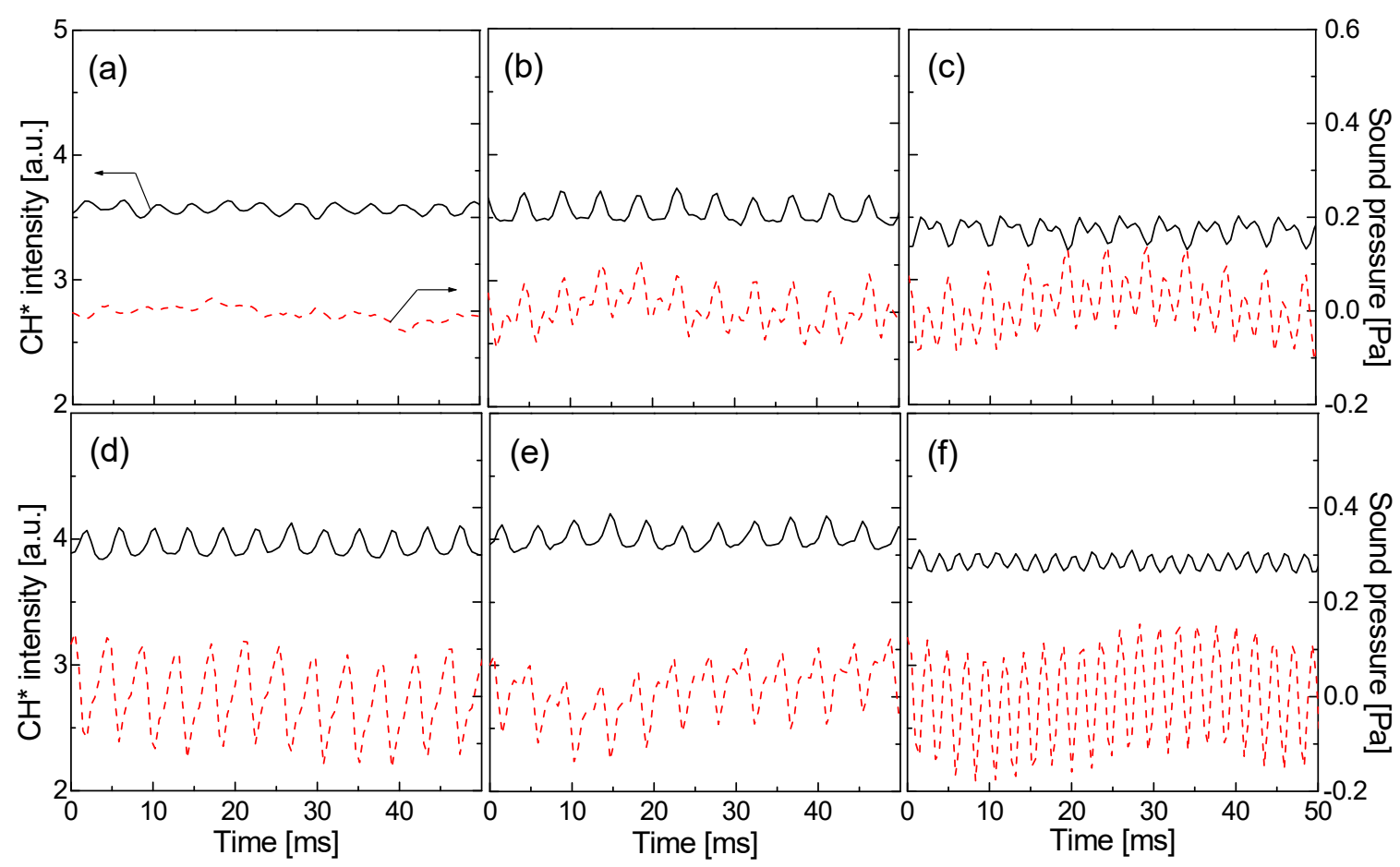

Figure 9. Comparison of $\mathrm{CH}^{*}$ chemiluminescence and sound pressure with time; (a) $(\phi=$ 1.12, $\left.U_{p}=2.6 \mathrm{~m} / \mathrm{s}\right),(\mathrm{b})(1.14,2.6 \mathrm{~m} / \mathrm{s}),(\mathrm{c})(1.16,2.6 \mathrm{~m} / \mathrm{s}),(\mathrm{d})(1.12,3.2 \mathrm{~m} / \mathrm{s}),(\mathrm{e})(1.14,3.2$ $\mathrm{m} / \mathrm{s})$, and (f) $(1.16,3.2 \mathrm{~m} / \mathrm{s})$. 


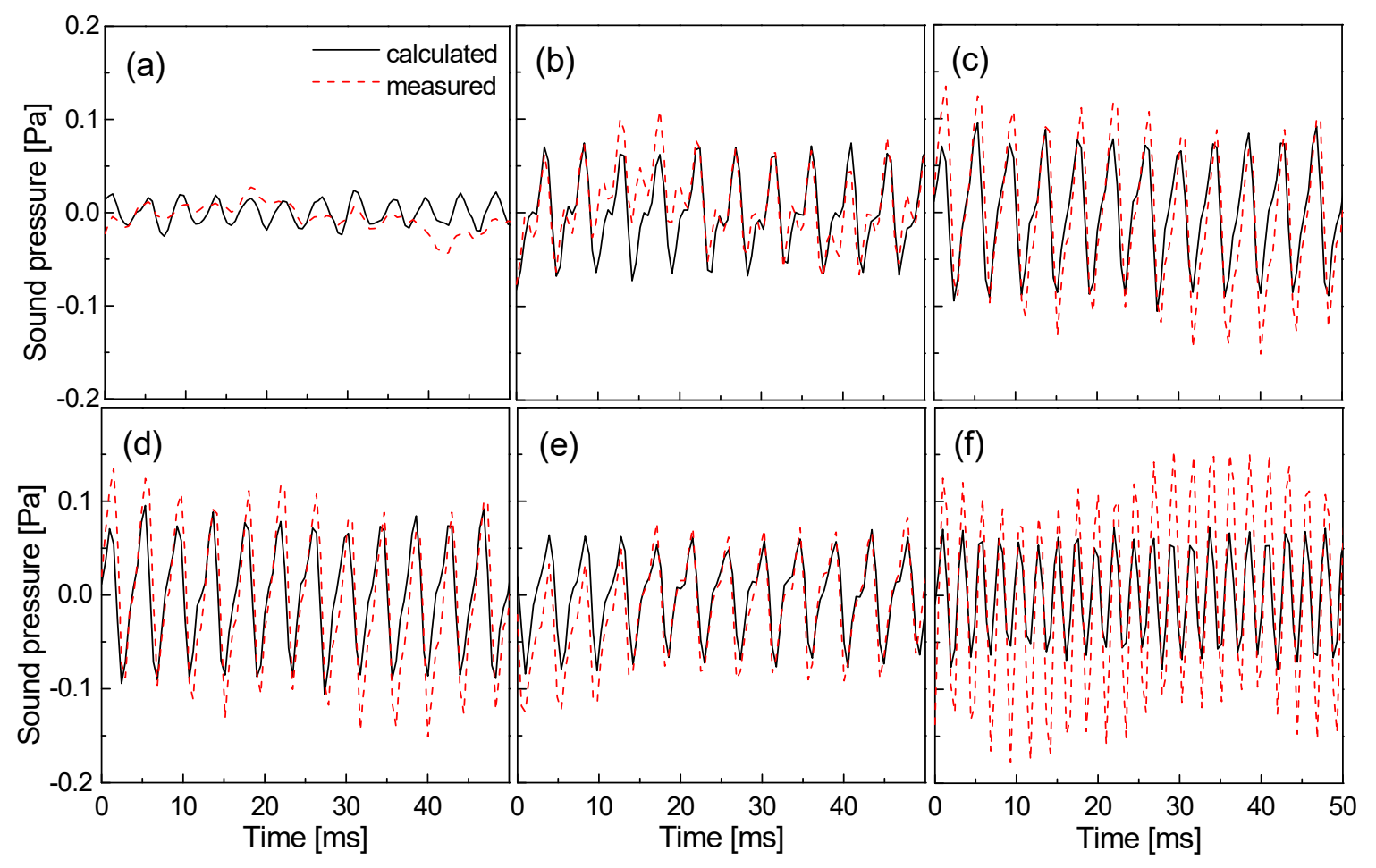

Figure 10. Comparison between measured and calculated sound pressures with time; (a) $(\phi$ $\left.=1.12, U_{p}=2.6 \mathrm{~m} / \mathrm{s}\right),(\mathrm{b})(1.14,2.6 \mathrm{~m} / \mathrm{s}),(\mathrm{c})(1.16,2.6 \mathrm{~m} / \mathrm{s}),(\mathrm{d})(1.12,3.2 \mathrm{~m} / \mathrm{s}),(\mathrm{e})(1.14,3.2$ $\mathrm{m} / \mathrm{s})$, and (f) $(1.16,3.2 \mathrm{~m} / \mathrm{s})$. 


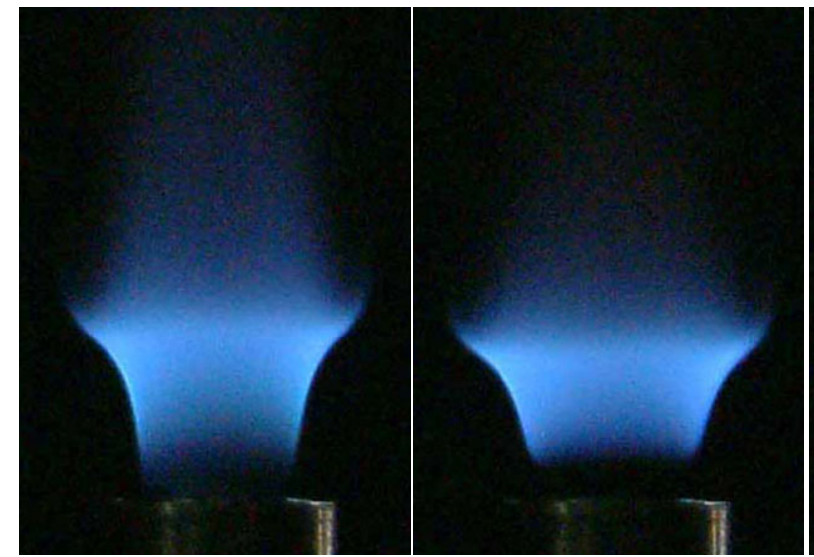

(a)

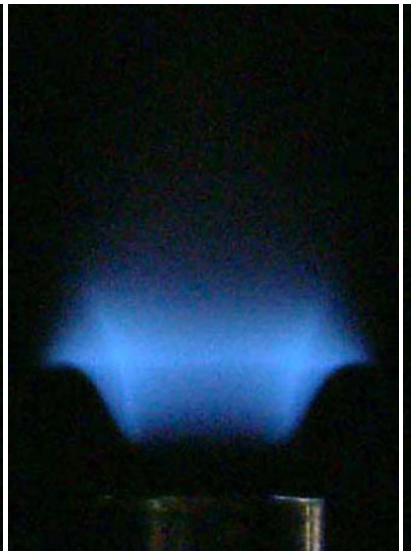

(c)

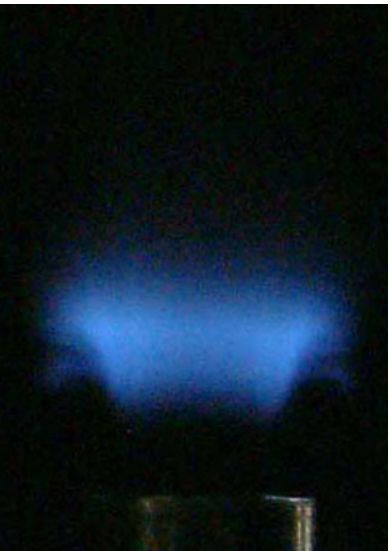

(d)

Figure 11. Direct photographs of flames with air velocity in inner nozzle for $\phi=1.14$ and $U_{p}$ $=2.5 \mathrm{~m} / \mathrm{s}$; (a) $U_{a}=0.01 \mathrm{~m} / \mathrm{s}$, (b) $0.085 \mathrm{~m} / \mathrm{s}$, (c) $0.10 \mathrm{~m} / \mathrm{s}$, and (d) $0.13 \mathrm{~m} / \mathrm{s}$. 


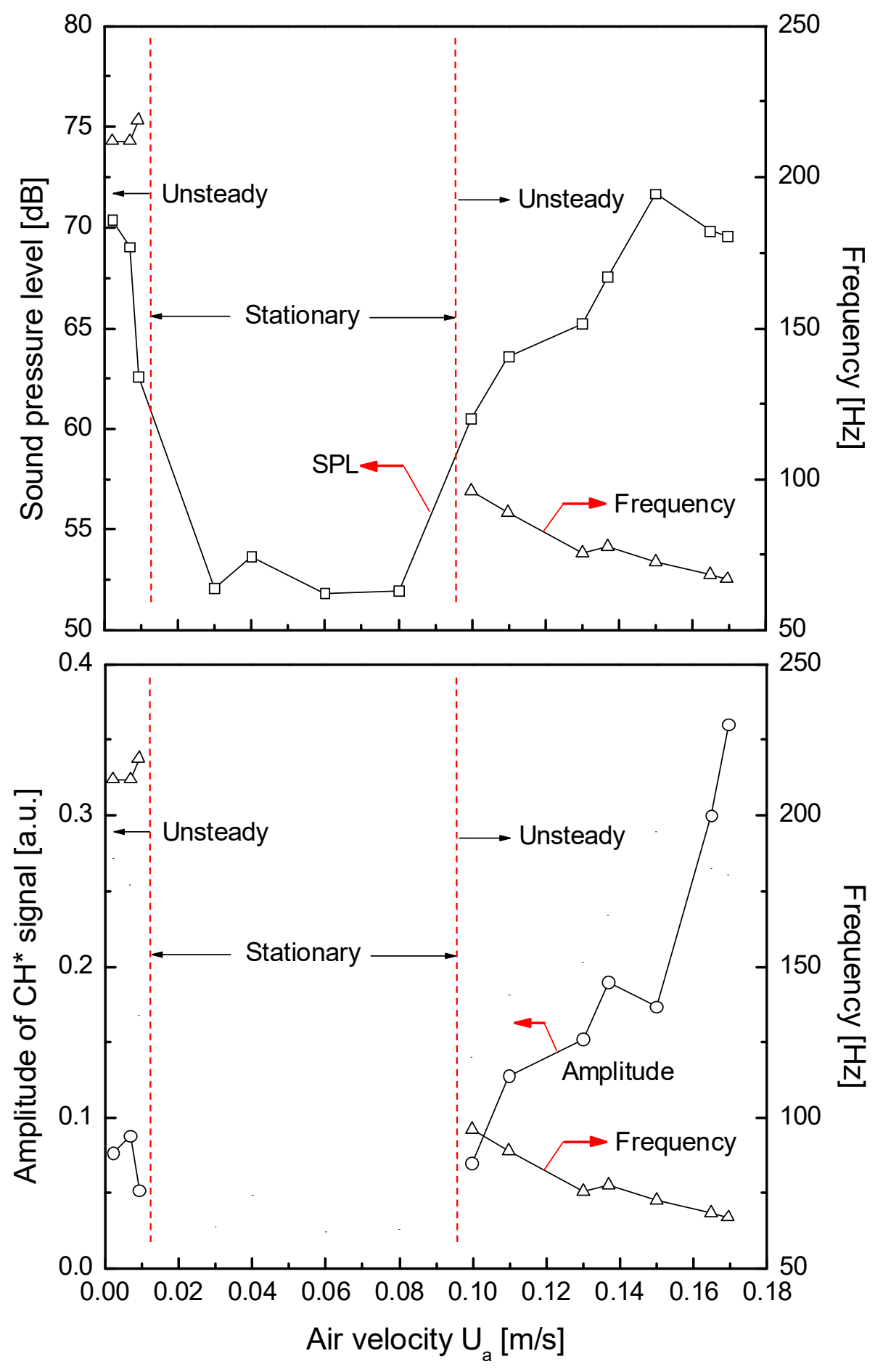

Figure 12. Sound pressure level, frequency, and amplitude of $\mathrm{CH}^{*}$ signal as function of air velocity in inner tube for $\phi=1.14$ and $U_{p}=2.5 \mathrm{~m} / \mathrm{s}$. 


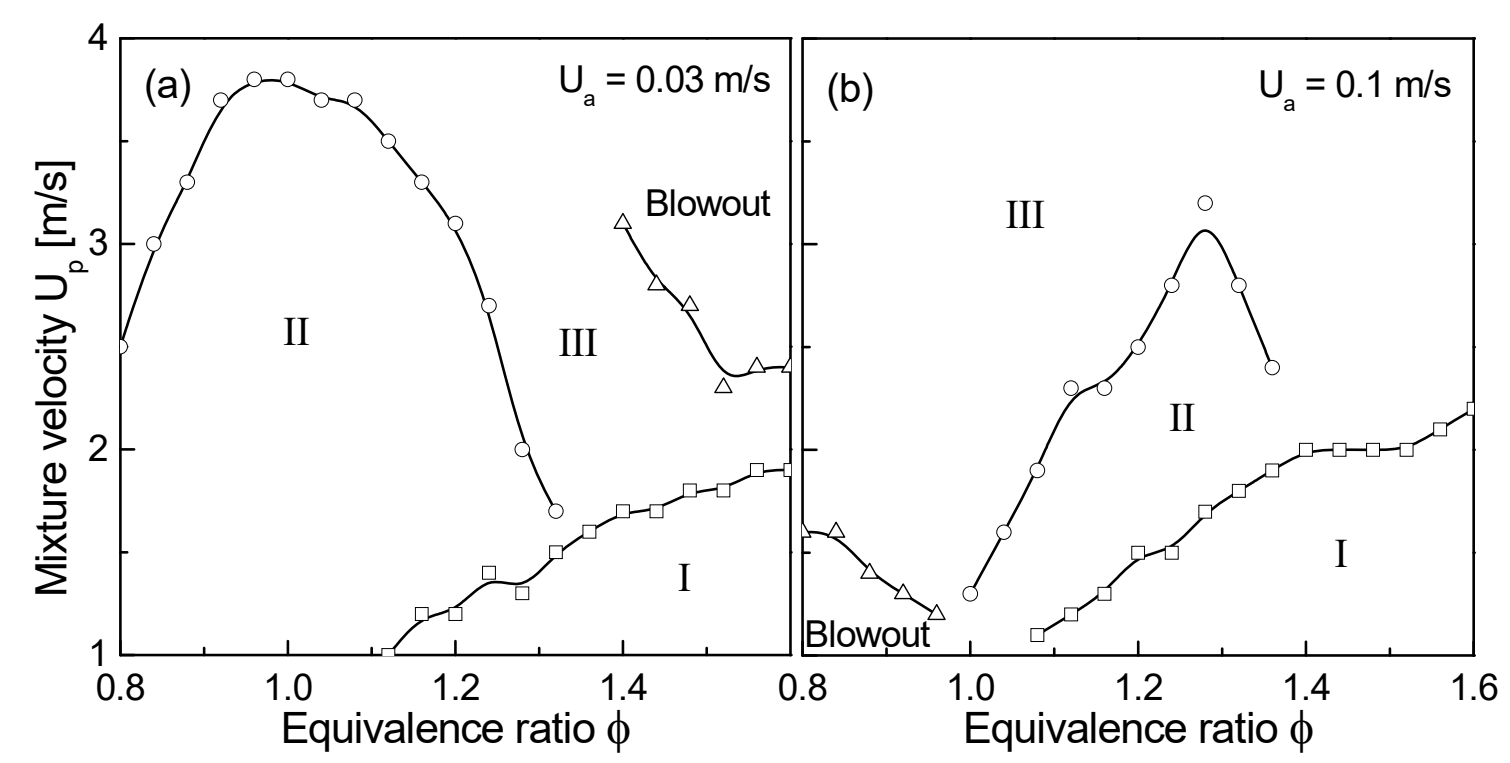

Figure 13. Flame stability diagrams for air velocity in inner nozzle of (a) $U_{a}=0.03 \mathrm{~m} / \mathrm{s}$ and (b) $0.1 \mathrm{~m} / \mathrm{s}$ (regime I; ring or conical shape, regime II; steady crown shape, and regime III; unsteady crown shape). 